\title{
Alterations in Lipid-Lipoprotein Fractions and Antioxidant Status by Lycopene and its Blends with Rice Bran Oil in Nutritionally Induced Hyperlipidemic Animal Model
}

\author{
Komal Chauhan*
}

\author{
Department of Food Science and Technology, National Institute of Food Technology and Entrepreneurship \\ and Management, Kundli, Sonepat, Haryana, India
}

\begin{abstract}
Nutrition Transition in the latter half of $20^{\text {th }}$ century has prompted profound shift from traditional dietary pattern of fibre rich foods to increased consumption of energy dense, high fat and low fibre foods. Resultant oblivious nutritional environment coupled with physical inactivity has abridged the gap between health and chronic diseases. Consequently, the paradigm of treatment from pharmaceuticals has shifted to neutraceuticals and a large proportion of populace is resorting to cost effective treatments from natural sources that can contribute effectually in combating these dreadful diseases. The present study was undertaken to evaluate the efficacy of blends of lycopene and rice bran oil (RBO) on alteration in lipid metabolism and oxidative stress biomarkers in high fat high cholesterol diet fed albino rats. The rats were supplemented with lycopene $(30 \mathrm{mg} / \mathrm{kg} /$ day) singly and blend of lycopene $(30 \mathrm{mg} / \mathrm{kg} /$ day) and rice bran oil $(100 \mathrm{ml} / \mathrm{kg} / \mathrm{day})$ for 6 weeks. Results indicate that lycopene enriched diets significantly $(p \leq 0.05)$ improved altered parameters, however, the effect was more pronounced in animals reared on blends of lycopene and RBO. The therapeutic potential of lycopene and RBO can be tapped as preventive and protective therapy against the detrimental effects of high fat diets consumed globally.
\end{abstract}

Keywords: Lycopene, Hyperlipidemia, Oxidative Stress, Rice Bran Oil, Antioxidants.

\section{INTRODUCTION}

Hyperlipidemia is a major causative factor to atherosclerosis and allied ailments viz. diabetes, obesity, cardiovascular, stroke henceforth metabolic syndrome [1]. The spell of these diseases is increasing alarmingly worldwide due to rapid urbanization and globalization of unhealthy life styles [2]. Indeed the "Nutrition Transition" coupled with sedentary lifestyle have increased the burden of chronic diseases in the latter half of $20^{\text {th }}$ century [3]. The potential disparity between our ancestral and contemporary dietary regimes has driven the resultant change weakening the defense mechanism. Fat mediated oxidative stress build up is the mainstay for increasing the myriad of complications and the emerging trends of degenerative diseases [4]. The focus of the research for last few decades was on pharmacological compounds that can alter the metabolism or enzymatic reactions to attenuate the progression of cardiovascular events and associated clinical manifestations [5]. These drugs though effective contribute to adverse effects thereby affecting the overall health besides executing financial burden. Comprehending the need, efforts to develop cost effective alternative treatments stimulated the search for novel compounds from natural fruits, vegetables or underutilized herbs. Several bioactive

*Address correspondence to this author at the Department of Food Science and Technology, National Institute of Food Technology and Entrepreneurship and Management, Kundli, Sonepat, Haryana, India; Tel: 91-1302281218, 91-9466000672; E-mail: komal.niftem@gmail.com compounds with biological benefits are garnering attention to mitigate the ill effects of unhealthy diets [6-9].

Lycopene, deep red carotenoid present in tomatoes, pink grapefruit, guava and watermelon and processed tomato (tomato sauce, puree, pasta) products accounts for more than $85 \%$ of all the dietary sources [10]. Amongst the 600 carotenoids discovered, lycopene with 11 conjugated and 2 non conjugated double bonds is the most efficient singlet oxygen quencher [11]. Furthermore it has the highest antioxidant activity in cell protection against free radicals [12-13]. It has wide potential in as neutraceuticals in foods and pharmaceutical industry thus having a high therapeutic index. Its high stability against degradation and isomerization during commercial processing makes it a molecule worth harnessing [14]. Over the last few decades lycopene has been subjected to many scientific and medical studies to determine the extent of its long purported health benefits with some evidence suggesting that regular consumption of lycopene may have an impact on clinical outcome of various chronic diseases [10].

Rice bran oil (RBO) is obtained from the outer brown layer of rice and is widely consumed globally. The uniqueness of the oil in comparison to the other edible oil is endorsed to its balanced fatty acid composition and idyllic proportion of polyunsaturated and saturated fatty acids and linoleic acid (LA) to alpha linoleic acid (ALNA) ratio [15]. Studies have shown that it has several health benefits and can be used as a 
preventive therapy against chronic diseases. These benefits are attributed to the presence of high content $(1.5-2.6 \%)$ of unsaponifiable matter viz. oryzanol, tocotrienols and tocopherols [16-18]. Furthermore, besides ameliorating the diseases these active principles impart higher oxidative stability and longer shelf life to oil thus RBO could become an important functional food in the times to come [19].

Though the therapeutic index of lycopene and rice bran oil on various chronic diseases has been studied extensively, however, no work has been elucidated to study the combined effect of two. High fat high cholesterol rich diet simulates the cafeteria diets and thus predisposing the masses to health hazards and complications associated with chronic diseases to varying degrees. Therefore, the study was planned with an avowed aim of biochemical evaluation of lipid and oxidative stress modulating effects of lycopene singly and in blends with RBO in hyperlipidemia induced oxidative stress in albino rats.

\section{MATERIALS AND METHODS}

\subsection{Chemicals}

The chemicals used in the study were of analytical grade, procured from Sigma, Merck, BDH and Qualigens. Diagnostic kits for the estimation of serum and hepatic biomarkers were purchased from Erba Mannheim (Transasia Bio-Medicals Ltd. Daman, India). RBO was provided at gratis from A.P Solvex Ltd, Dhuri, India. Lycored (Lycopene) was provided as generous gift from Jagsonpal Pharmaceutical Ltd, Delhi, India

\subsection{Experimental Animals}

Adult male albino rats of wistar strain weighing around $175.8 \pm 8.73 \mathrm{~g}$ to $179.1 \pm 7.70 \mathrm{~g}$ obtained from CCSHAU, HISAR, India were used in this study. They were housed in polypropylene cages over husk bedding and a 12-hour light and dark cycle was maintained throughout the experimental period of 42 days. Rats were fed a commercial pelleted diet (Hindustan Lever Limited, Chandigarh, India) and water, adlibitum during acclimatization period of one week before the commencement of experiment. The experiments were conducted according to the ethical norms approved by CPCSEA, and Institutional Animal Ethics Committee guidelines.

\subsection{Experimental Design}

The animals were divided into four groups of six animals each. Group A served as vehicle control and was reared on isoenergic $(\sim 3600 \mathrm{C})$ normal fat diet (NFD), containing $60 \%$ carbohydrates, $20 \%$ protein, $5 \%$ fat, $5 \%$ fibre, and $10 \%$ mixture of vitamins and minerals [20]. Rats in Group B were supplemented high fat high cholesterol (HFHC) diet, formulated by incorporating $84.5 \%$ normal fat diet; $15 \%$ coconut oil $(\mathrm{w} / \mathrm{w})$ and $0.5 \%$ cholesterol $(\mathrm{w} / \mathrm{w})$. Rats in Group C were fed HFHC diet and lycopene $(0.03 \mathrm{~g} / \mathrm{kg} /$ day $)$ and Group D animals were treated with HFHC diet along with coadministration of lycopene $(0.03 \mathrm{~g} / \mathrm{kg} /$ day $)$ and rice bran oil $(100 \mathrm{ml} / \mathrm{kg} /$ day $)$. Lycopene in a gelatinous capsule, lycored (Jagsonpal Pharmaceutical Ltd, Delhi, India) was reconstituted in RBO (A.P Solvex Ltd, Dhuri, India) to appropriate working concentration and then admixed with diet.

\subsection{Acute Toxicity Study}

Acute oral toxicity was performed as per Organisation for Economic Cooperation and Development [21] (OECD 2001). After the dietary supplementation of lycopene singly and in blends with RBO, animals were observed individually for general behavioural. The pattern of observation was at least once during the first 30 minutes followed periodically for 24 hours. Special attention was given during first four hours daily and thereafter for a period of 14 days.

\subsection{Collection of Samples for Analysis}

The blood was collected in heparinized prechilled vials from retrorbital plexus, centrifuged at $3000 \mathrm{~g}$ at $4^{0} \mathrm{C}$ for 10 minutes to obtain serum which was stored at $-80^{\circ} \mathrm{C}$ for further evaluation of haematological parameters. Thereafter, the animals were sacrificed by cervical decapitation. The organs were removed, freed of adhering tissues, washed with ice cold physiological saline, blotted dry and weighed. A small part of the tissues were excised, minced and used for enzyme activity assay and other biochemical evaluation. The remaining tissues were stored at $-80^{\circ} \mathrm{C}$ for further biochemical analysis.

\subsection{Biochemical Analysis of Serum}

Serum was subjected to biochemical evaluation of various parameters viz. total cholesterol (TC), triglycerides (TG); HDL-cholesterol using diagnostic kits (Erba Mannheim Transasia Bio-Medicals Ltd. Daman, India). VLDL and LDL-cholesterol were calculated as per Friedewald's equation [22]: VLDL-C = $\mathrm{TG} / 5$ and LDL-C =TC - (HDL-C + VLDL-C). Atherogenic index was calculated by the following 
formula: $\mathrm{Al}=($ Total-C $-\mathrm{HDL}-\mathrm{C}) / \mathrm{HDL}-\mathrm{C}$. Serum uric acid was estimated by Caraway [23], Serum glutamate pyruvate transaminases (SGPT) and serum glutamate oxaloacetate transaminases (SGOT) were measured spectrophotometrically by utilizing the method of Reitman and Frankel [24]. Alkaline Phosphatase was determined by the method of Belfield and Goldberg [25].

Hepatic and faecal lipids were extracted in chloroform: methanol (2:1) (Folch et al., 1957) and dried [26]. Dried lipid extract was dissolved in 1\% triton $\mathrm{x} 100^{25}$ and total cholesterol (TC), triglycerides (TG) were estimated using above mentioned diagnostic kits. Faecal bile acids (cholic acid and deoxycholic acid) were estimated using the method of Mosback et al., 1954 [27].

\subsection{Biochemical Analysis of Tissue Homogenates}

For enzyme activity assay, $0.8-1.0 \mathrm{~g}$ of hepatic tissue was minced and homogenized in 10 times its volume of $0.2 \mathrm{M} / \mathrm{L}$ tris $\mathrm{HCl}(\mathrm{pH}=8.0)$ containing $0.5 \mathrm{M} / \mathrm{L}$ $\mathrm{CaCl}_{2}$ using Potter Elevehjem apparatus at $0-4^{0} \mathrm{C}$ using motor driven teflon pestle rotated at 3000rpm. The homogenate was centrifuged at $10000 \mathrm{~g}$ for 30 minutes at $4^{\circ} \mathrm{C}$ and $3 / 4$ th of the volume was carefully drawn using Pasteur's pipette. The supernatants were stored at $-80^{\circ} \mathrm{C}$ until analysis.

Enzyme assay involved, lipid peroxidation (TBARS) [28]; serum TBARS [29]; red cell reduced glutathione [30]; hepatic TBARS [31]; reduced glutathione (GSH) [32] and antioxidant enzymes viz. glutathione peroxidase (GSHPx) [33]; catalase (CAT) [34] and superoxide dismutase (SOD) [35]. The protein content was estimated by Lowry method [36].

\subsection{Lipid Metabolising Enzymes}

Activity of lipoprotein lipase (LPL) was determined by the method described by Korn (1962) [37], expressed as $\mathrm{mmol}$ of glycerol liberated $/ \mathrm{h} / \mathrm{min} / \mathrm{ml}$ plasma. The lecithin-cholesterol acyl transferase (LCAT) was assayed by the method of Hitz et al., 1983 [38], expressed as $\mu \mathrm{g}$ of cholesterol esterified $/ \mathrm{min} / \mathrm{l}$. Cholesterol ester synthetase (CES) was estimated by Kothari et al., 1973 [39]. Assay of hepatic triglyceride lipase (HTGL) activity was estimated using the method of Schmidt et al., 1974 [40], expressed as $\mu \mathrm{g}$ of free fatty acids released $/ \mathrm{min} / \mathrm{mg}$ protein. HMG Co.A reductase activity was determined by the method of Rao and Ramakrishnan [41].

\subsection{Statistical Analysis}

Results were expressed as mean \pm SEM for six animals in each group. The data was statistically evaluated using SPSS (version 16) for one-way ANOVA followed by LSD test. $p \leq 0.05$ was considered statistically significant.

\section{RESULTS}

\subsection{Nutritional Parameters}

The effect of lycopene enriched diets on nutritional parameters is shown in Table 1.

Body weights of HFHC diet fed group increased significantly $(p \leq 0.05)$ during the feeding period $(72.1 \%)$. Inclusion of lycopene alone $(63.7 \%)$ and in blend with RBO $(59.5 \%)$ to HFHC diets to rats showed a decreasing trend in body weights. A similar trend was observed in relative liver size (RLS) which showed a significant $(p \leq 0.05) \quad$ increase in group B

Table 1: Effect of Lycopene Enriched Diets on Nutritional Parameters of Experimental Animals

\begin{tabular}{|c|c|c|c|}
\hline $\begin{array}{c}\text { Dietary } \\
\text { groups }\end{array}$ & Body weight gain (\%) & $\begin{array}{c}\text { Relative liver size } \\
\text { (liver wt (g)/100g body wt) }\end{array}$ & $\begin{array}{c}\text { Relative food consumption } \\
\text { (g/100g body wt) }\end{array}$ \\
\hline \hline A & 46.6 & $3.1 \pm 0.15$ & $7.5 \pm 0.54$ \\
\hline B & $72.1^{\mathrm{a}}$ & $4.1 \pm 0.28^{\mathrm{a}}$ & $7.6 \pm 0.38^{*}$ \\
\hline C & $63.7^{\mathrm{b}}$ & $3.9 \pm 0.24^{*}$ & $7.3 \pm 0.28^{*}$ \\
\hline D & $59.5^{\mathrm{b}}$ & $2.9 \pm 0.09^{\mathrm{b}}$ & $6.8 \pm 0.26^{\mathrm{b}}$ \\
\hline
\end{tabular}

[Values: Mean \pm SEM of 6 rats in each dietary group]

A- Isoenergic normal fat group.

B-High fat- high cholesterol group (HFHC).

C- High fat- high cholesterol group +Lycopene (HFHC-LY).

D- High fat- high cholesterol group +Lycopene+RBO (HFHC-LY-RBO)

${ }^{a} p \leq 0.05$ Significant between Group-A and Group- B.

${ }_{p} p \leq 0.05$ Significant between Group- B and Group C and D.

$*$ : Non Significant $(p \geq 0.05)$. 
$(4.1 \pm 0.28 \mathrm{~g} / 100 \mathrm{~g}$ body weight). Lycopene treated rats on the contrary restored the relative liver size, with maximal decrease in Group-D $(2.9 \pm 0.09 \mathrm{~g} / 100 \mathrm{~g}$ body weight). The relative food consumption (RFC) of animals during experimental period did not show much variation among various treatments. Coadministration of lycopene and RBO along with HFHC diet resulted in a significant decrease $(p \leq 0.05)(6.8 \pm 0.26 \mathrm{~g} / 100 \mathrm{~g}$ body weight) in comparison to Group $B$ fed HFHC $\operatorname{diet}(7.6 \pm 0.38 \mathrm{~g} / 100 \mathrm{~g}$ body weight).

\subsection{Lipid-Lipoprotein Profile}

HFHC diets had a hyperlipidemic and hypercholesterolemic effect as evident from the serum and hepatic lipid profile (free fatty acids, triglycerides, phospholipids) of the experimental animals Table 2 and Figure 1.

\subsubsection{Serum Lipid Status}

The lipid components registered a significant increase $(p \leq 0.05)$ in the animal group fed on HFHC diet

Table 2: Effect of Lycopene Enriched Diets on Nutritional Parameters of Experimental Animals

\begin{tabular}{|c|c|c|c|c|c|c|c|c|}
\hline \multirow{3}{*}{$\begin{array}{l}\text { Dietary } \\
\text { groups }\end{array}$} & \multicolumn{2}{|c|}{ Free fatty acids } & \multicolumn{2}{|c|}{ Triglycerides } & \multicolumn{2}{|c|}{ Phospholipids } & \multicolumn{2}{|c|}{ Cholesterol } \\
\hline & Serum & Hepatic & Serum & Hepatic & Serum & Hepatic & Serum & Hepatic \\
\hline & $(\mathrm{mg} / 100 \mathrm{ml})$ & $(\mathrm{mg} / 100 \mathrm{~g})$ & $(\mathrm{mg} / 100 \mathrm{ml})$ & $(\mathrm{mg} / 100 \mathrm{~g})$ & (mg/100ml) & $(\mathrm{mg} / 100 \mathrm{~g})$ & (mg/100ml) & $(\mathrm{mg} / 100 \mathrm{~g})$ \\
\hline$A$ & $11.8 \pm 0.06$ & $0.59 \pm 0.024$ & $84.0 \pm 1.31$ & $429.8 \pm 3.95$ & $129.1 \pm 1.26$ & $1800.0 \pm 3.93$ & $77.6 \pm 2.38$ & $373.8 \pm 7.64$ \\
\hline$B$ & $19.8 \pm 0.52^{a}$ & $0.85 \pm 0.011^{a}$ & $106.3 \pm 3.18^{a}$ & $505.8 \pm 3.65^{a}$ & $147.5 \pm 1.51^{a}$ & $2198.5 \pm 4.38^{a}$ & $100.1 \pm 3.36^{a}$ & $420.7 \pm 7.90^{a}$ \\
\hline $\mathrm{C}$ & $15.5 \pm 0.52^{b}$ & $0.78 \pm 0.011^{b}$ & $89.2 \pm 4.06^{b}$ & $453.5 \pm 11.04^{b}$ & $138.9 \pm 2.27^{b}$ & $1853.5 \pm 11.68^{b}$ & $84.3 \pm 5.46^{b}$ & $380.4 \pm 6.63^{b}$ \\
\hline $\mathrm{D}$ & $13.6 \pm 0.14^{b}$ & $0.71 \pm 0.014^{b}$ & $87.7 \pm 0.43^{b}$ & $435.6 \pm 0.79^{b}$ & $124.7 \pm 0.96^{b}$ & $1899.9 \pm 2.23^{b}$ & $73.7 \pm 0.35^{b}$ & $369.2 \pm 1.13^{b}$ \\
\hline
\end{tabular}

[Values: Mean \pm SEM of 6 rats in each dietary group].

A- Isoenergic normal fat group.

B-High fat- high cholesterol group (HFHC).

C- High fat- high cholesterol group +Lycopene (HFHC-LY).

D- High fat- high cholesterol group + Lycopene+RBO (HFHC-LY-RBO).

${ }^{a} \mathrm{p} \leq 0.05$ Significant between Group- A and Group-B.

${ }_{p} \leq 0.05$ Significant between Group- B and Group-C and Group- D.

$*$ : Non Significant $(p \geq 0.05)$.

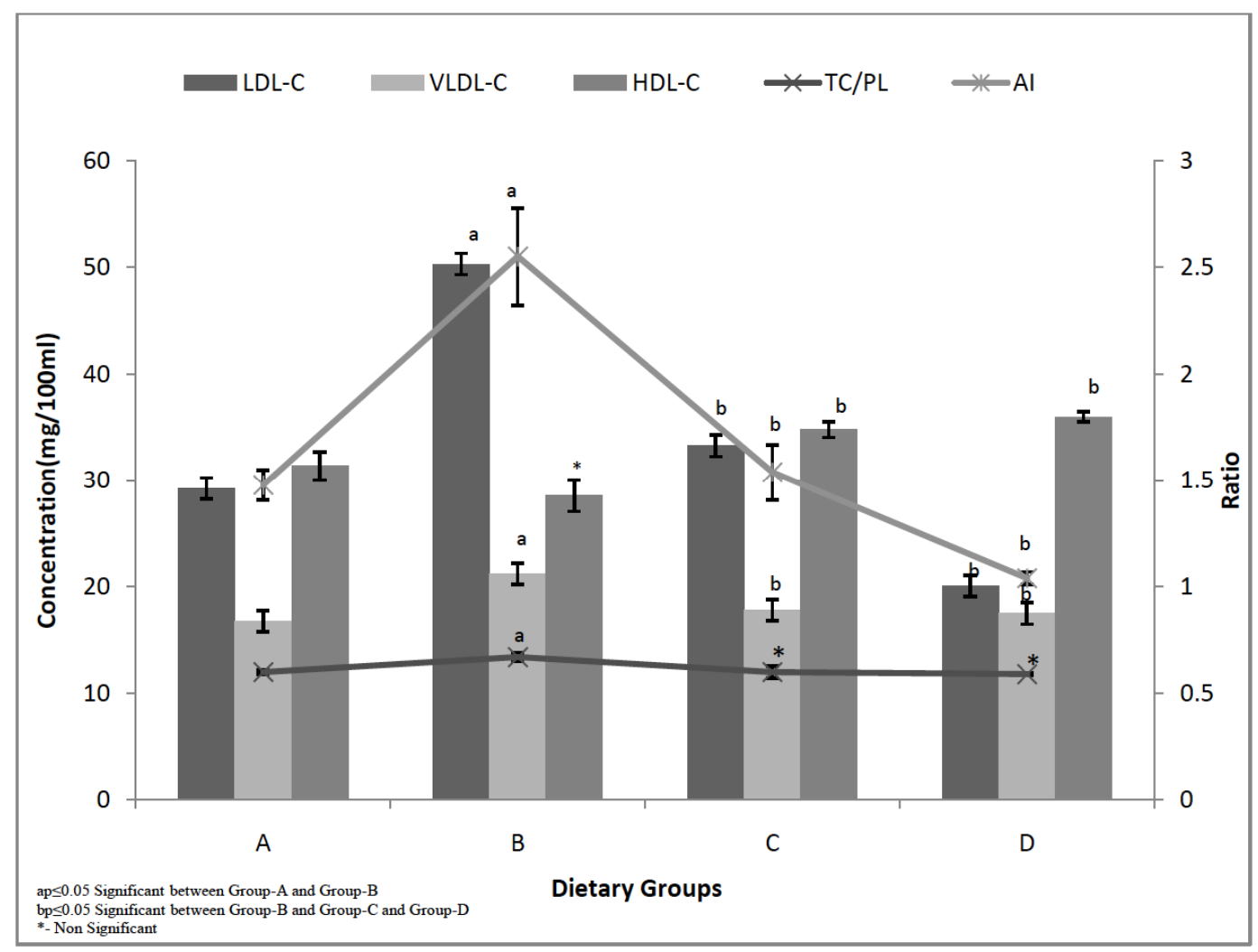

Figure 1: Effect of Lycopene Enriched Diets on Serum Lipoprotein fractions and Lipid Indices of Experimental Animals. Values (Mean \pm SEM) of 6 rats in each group. 
vis-à-vis those fed isoenergic normal fat diet. However, the upsurge induced by HFHC diet was neutralized $(p \leq 0.05)$ in other experimental groups fed on diets encompassing lycopene either singly or in combination with $\mathrm{RBO}$, thereby significantly decreasing the various levels of serum lipid parameters $(p \leq 0.05)$ as evident from the Table 2.

\subsubsection{Hepatic Lipid Status}

A significant increase $(p \leq 0.05)$ was observed in various hepatic lipid parameters viz. free fatty acids, triglycerides, phospholipids and total cholesterol of rats fed HFHC diets (Group B) as compared to the ones fed isoenergic normal fat diet (Group-A) as evident from the Table 2. However, supplementation of HFHC diet with lycopene either singly or coadministered with RBO resulted in significant decrease $(p \leq 0.05)$ in various hepatic mean lipid levels.

\subsubsection{Serum Total and Lipoprotein Cholesterol}

Hypercholesterolemic effect was observed in the experimental groups fed $\mathrm{HFHC}$ diets resulting in significant increase $(p \leq 0.05)$ in mean TC, LDL-C and VLDL-C as compared to the ones fed isoenergic normal fat diet as evident from the Table 2/Figure 1. Concomitant feeding of lycopene enriched HFHC diets singly and admixed with RBO to animals had a hypocholesterolemic effect and significantly $(p \leq 0.05)$ improved the levels as compared to the ones fed HFHC diets.

On the contrary, there was a decreasing trend though insignificant $(p \geq 0.05)$ in mean HDL-C level in rats fed HFHC diet $(28.6 \pm 1.50 \mathrm{mg} / 100 \mathrm{ml})$ as compared to their control counter parts $(31.4 \pm 1.30 \mathrm{mg} / 100 \mathrm{ml})$. However, the dietary intervention with lycopene individually $(34.8 \pm 0.72 \mathrm{mg} / 100 \mathrm{ml})$ and in blend with RBO $(36.0 \pm 0.47 \mathrm{mg} / 100 \mathrm{ml})$ tended to nullify the effect and significantly $(p \leq 0.05)$ raised mean HDL-C levels as compared to the animals fed HFHC diets as evident from the Figure 1.

\subsubsection{Serum Lipid Indices}

Serum lipid indices viz. TC/PL (Total$\mathrm{C} /$ Phospholipids) and atherogenic index (Al) (Figure 1) indicate a significant increase $(p \leq 0.05)$ in mean TC/PL $(0.67 \pm 0.024)$ and $\mathrm{Al}(2.55 \pm 0.233)$ in Group B. In contrast, lycopene enriched HFHC diets singly and in blends significantly lowered TC/PL and $\mathrm{Al}(p \leq 0.05)$ in the experimental models.

\subsubsection{Lipid Metabolising Enzymes}

Figure 2 depicts the activity of lipid metabolising enzymes in experimental animals. A significant decrease $(p \leq 0.05)$ in the activity of LPL $(49.1 \%)$ was observed in rats reared on HFHC diets (Group-B) as

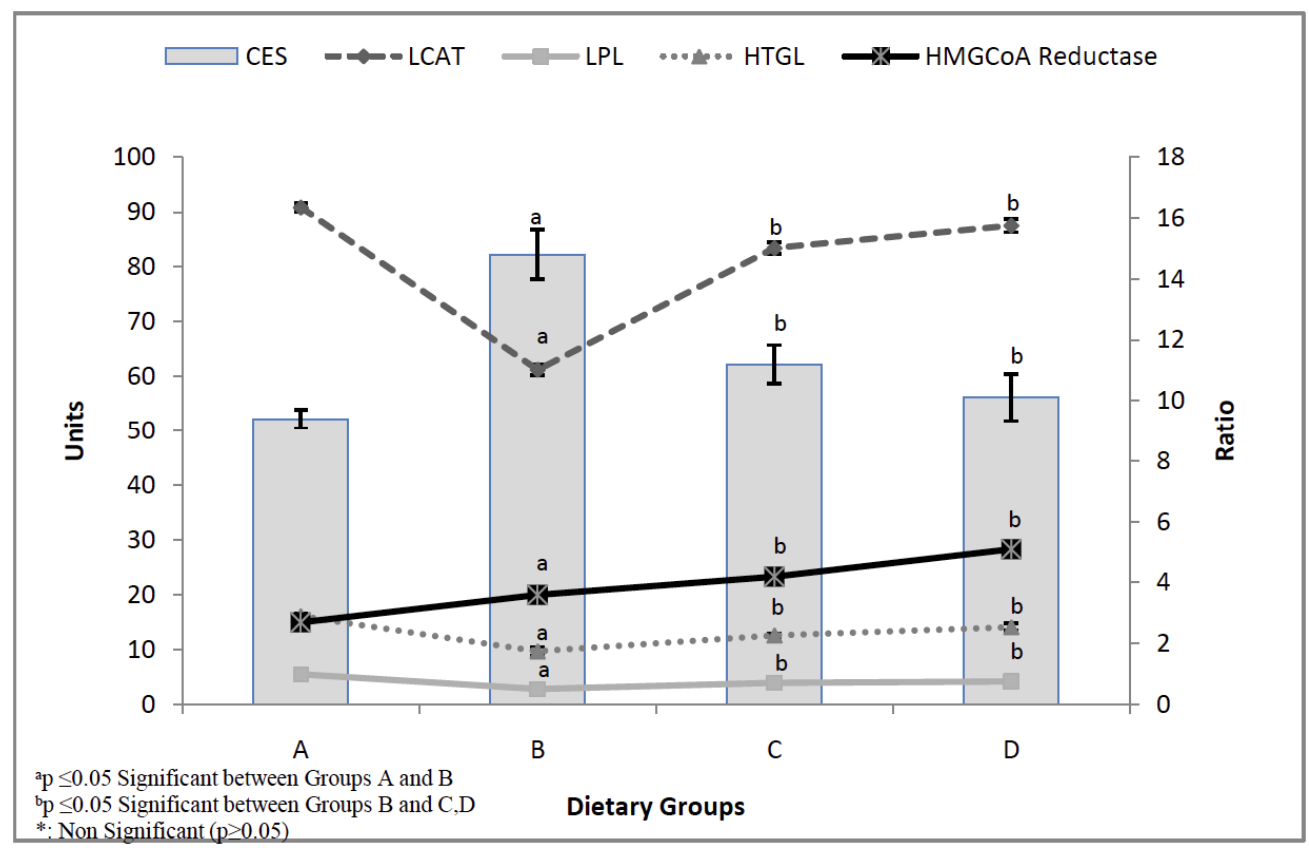

Figure 2: Effect of Lycopene Enriched Diets on Lipid Metabolizing Enzymes in Experimental Animals.

Values (Mean \pm SEM) of 6 rats in each group.

(LPL-mmol of glycerol liberated/h/min/ml plasma; LCAT- $\mu$ g of cholesterol esterified/min/L; HTGL- $\mu \mathrm{g}$ of free fatty acids released/min/mg protein; CES-mM of cholesterol esterified/h/100mg tissue; HMGCo.A reductase- HMGCoA/Mevalonate). 
Table 3: Effect of Lycopene Enriched Diets on Bilirubin, Bile Acids and Faecal Lipids of Experimental Animals

\begin{tabular}{|c|c|c|c|c|c|c|c|c|}
\hline \multirow{2}{*}{$\begin{array}{l}\text { Dietary } \\
\text { Groups }\end{array}$} & \multicolumn{3}{|c|}{ Bilirubin (mg/dl) } & \multicolumn{2}{|c|}{ Bile Acid ( $\mu \mathrm{g} / \mathrm{gfaeces})$} & \multicolumn{3}{|c|}{ Faecal Lipids (mg/g faeces) } \\
\hline & Total & Direct & Indirect & Cholic Acid & $\begin{array}{c}\text { Deoxy } \\
\text { Cholic acid }\end{array}$ & Total Lipids & Cholesterol & Triglycerides \\
\hline$A$ & $0.43 \pm 0.04$ & $0.25 \pm 0.02$ & $0.18 \pm 0.01$ & $30.1 \pm 1.51$ & $20.4 \pm 1.36$ & $30.4 \pm 1.64$ & $8.5 \pm 0.81$ & $8.9 \pm 0.46$ \\
\hline $\mathrm{B}$ & $0.78 \pm 0.07^{\mathrm{a}}$ & $0.5 \pm 0.03^{a}$ & $0.28 \pm 0.04^{a}$ & $32.6 \pm 2.16^{*}$ & $22.3 \pm 1.41^{*}$ & $32.5 \pm 1.78^{*}$ & $7.7 \pm 1.42^{*}$ & $10.1 \pm 0.64$ * \\
\hline C & $0.59 \pm 0.03^{b}$ & $0.35 \pm 0.05^{b}$ & $0.24 \pm 0.03^{*}$ & $40.1 \pm 1.83^{b}$ & $27.3 \pm 1.91^{\mathrm{b}}$ & $51.3 \pm 2.41^{b}$ & $13.5 \pm 1.86^{b}$ & $19.8 \pm 1.69^{b}$ \\
\hline D & $0.54 \pm 0.04^{b}$ & $0.36 \pm 0.06^{b}$ & $0.18 \pm 0.04^{b}$ & $45.7 \pm 1.79^{b}$ & $31.4 \pm 1.79^{b}$ & $57.9 \pm 1.46^{\mathrm{b}}$ & $18.6 \pm 1.90^{b}$ & $24.8 \pm 1.67^{b}$ \\
\hline
\end{tabular}

[Values: Mean \pm SEM of 6 rats in each dietary group].

A- Isoenergic normal fat group.

B-High fat- high cholesterol group (HFHC).

C- High fat- high cholesterol group +Lycopene (HFHC-LY).

D- High fat- high cholesterol group +Lycopene+RBO (HFHC-LY-RBO)

${ }^{a} p \leq 0.05$ Significant between Group- A and Group-B.

${ }^{b} \leq 0.05$ Significant between Group- B and Group-C and Group- D.

*: Non Significant $(p \geq 0.05)$.

compared to control rats (Group A). Lycopene treatment restored the activity of LPL in Group-C $(39.2 \%)$ and Group-D (50\%) resulting in significant increase $(p \leq 0.05)$ in comparison to Group-B. A similar trend was observed in the activity of LCAT, cholesterol metabolizing enzyme and HTGL, a lipoprotein catabolizing enzyme in HFHC diet reared animals with a simultaneous increase in cholesterol esterified synthetase (CES) activity. A significant restoration $(p \leq 0.05)$ in the activity of all the enzymes was observed in lycopene treated animals. The maximal increase in the activities of LCAT (42.9\%); HTGL (45.3\%) and decrease in CES (31.7\%) was seen in Group D coadministered with lycopene and rice bran oil.

\subsubsection{Faecal Lipids and Bile Acids}

There was no significant variation in faecal lipids and bile acid content of HFHC fed rats as compared to control. Animals reared on lycopene enriched HFHC diets singly and in admixture with $\mathrm{RBO}$ registered a significant increase in the excretion of faecal lipids and bile acids as depicted in Table 3.

\subsection{Bilirubin}

Compared to controls, HFHC diet fed experimental rats recorded a significant $(p \leq 0.05)$ increment in serum total, direct and indirect bilirubin levels. In contrast the altered levels were restored near to normal by lycopene enriched diets as depicted in Table 3.

\subsection{Oxidative Stress Status}

\subsubsection{Blood Oxidative Stress Status}

HFHC diet fed animals showed a significant increase $(p \leq 0.05)$ in the rate of lipid peroxidation (63.4\%); mean serum TBARS levels $(80 \%)$; uric acid
$(100 \%)$ with a concomitant decrease in mean red cell reduced glutathione $(17.4 \%)$ as compared to the corresponding control rats. A significant reduction $(p \leq 0.05)$ in the rate of lipid peroxidation was observed in the animals fed HFHC diets enriched with lycopene singly $(14.1 \%)$ and a combination of lycopene with RBO (14.8\%) as evident from the Figure 3 . In the same vein, the lycopene treated animals enticed a remarkable improvement in other oxidative stress markers. The mean serum TBARS levels $(20 \%$ and $15.9 \%)$; uric acid (10\% and $50 \%$ ) showed a decreasing trend with simultaneous increase in red cell reduced glutathione (13.4\% and 23.5\%) in Group-C and Group$\mathrm{D}$ respectively as depicted in the Figure 3 .

\subsubsection{Hepatic Oxidative Stress Status}

Hepatic mean TBARS concentration (14.4\%) increased synchronised with decrease in reduced glutathione $(28.9 \%)$ among the animals fed on HFHC diets as compared to the control fed isoenergic normal fat diet. On the contrary consumption of lycopene alone (9.1\% and $24.9 \%$ respectively) and in blends (16.1 and $6.3 \%$ respectively) with HFHC diets tended to reverse the trend and altered the hepatic levels of TBARS and reduced glutathione to near normal as compared to HFHC diet fed animals as shown in the Figure 3. However, the results were more pronounced $(p \leq 0.05)$ in group- $D$ as compared to group-C.

\subsubsection{Antioxidant Enzymes}

HFHC diets registered a decreasing trend in the activities of antioxidant enzymes in experimental animals as compared to their control counter parts as evident from the Table 4. Parallelly, the consumption of lycopene enriched HFHC diets singly and in blends with RBO significantly showed a marked improvement 


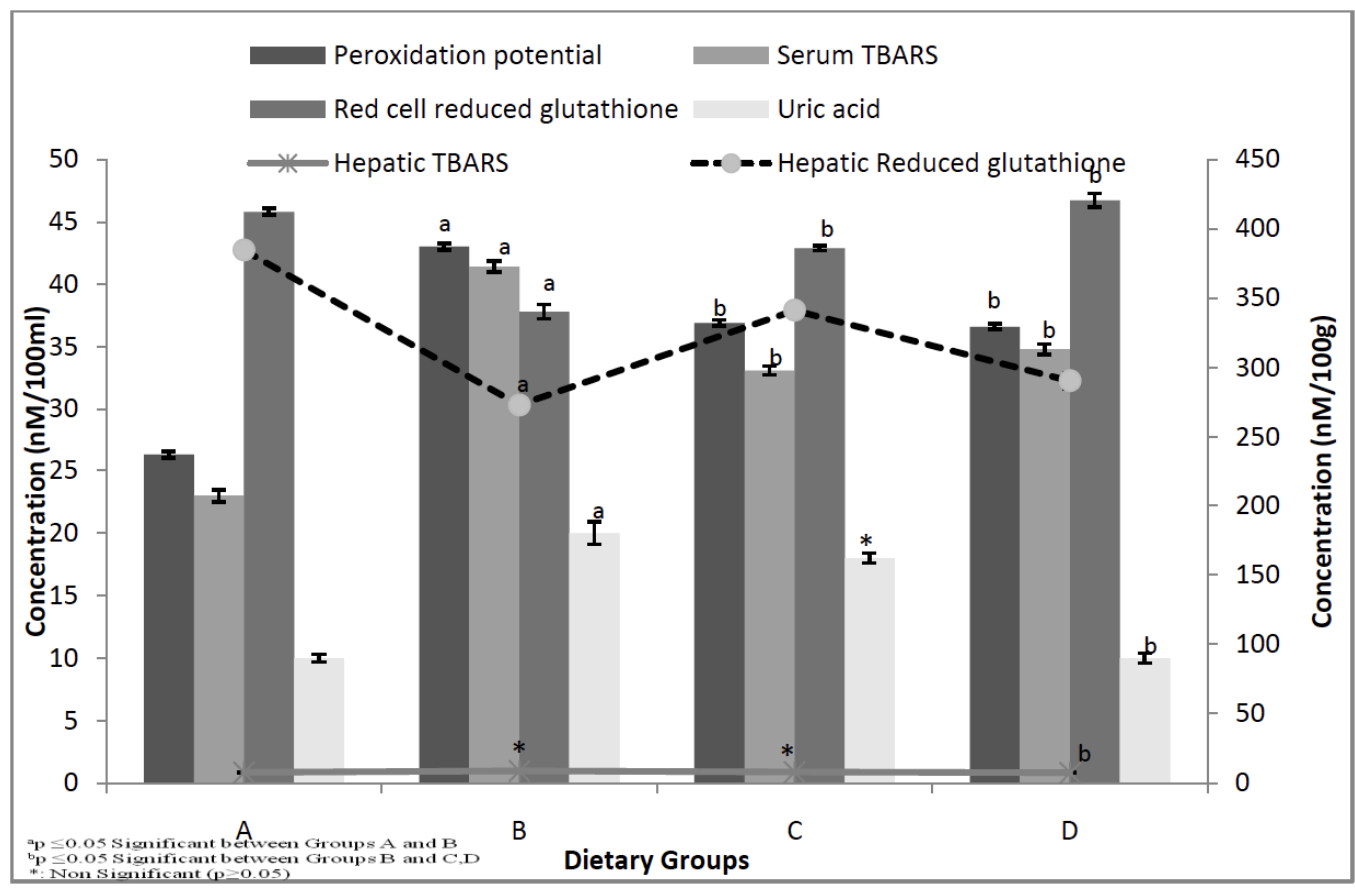

Figure 3: Effect of Lycopene Enriched Diets on Serum and Hepatic Oxidative Stress Status in Experimental Animals.

Values (Mean \pm SEM) of 6 rats in each group.

Table 4: Effect of Lycopene Enriched Diets on Oxidative Stress Status of Experimental Animals

\begin{tabular}{|c|c|c|c|c|c|c|c|}
\hline \multirow{2}{*}{$\begin{array}{l}\text { Dietary } \\
\text { Groups }\end{array}$} & \multirow{2}{*}{$\begin{array}{c}\text { GSHPx } \\
\text { (g of GSH } \\
\text { utilized } / \mathrm{min} / \mathrm{mg} \\
\text { protein) }\end{array}$} & \multirow{2}{*}{$\begin{array}{c}\text { CAT } \\
\text { (values } x \\
10^{-3} \text { units } / \mathrm{mg} \\
\text { protein) }\end{array}$} & \multirow{2}{*}{$\begin{array}{c}\text { SOD } \\
\text { (units/mg } \\
\text { protein) }\end{array}$} & \multicolumn{2}{|c|}{ Serum Transaminases } & \multirow{2}{*}{$\begin{array}{c}\text { ALP } \\
\text { (IU/L) }\end{array}$} & \multirow{2}{*}{$\begin{array}{l}\text { Total Proteins } \\
(\mathrm{mg} / \mathrm{ml})\end{array}$} \\
\hline & & & & $\begin{array}{l}\text { SGPT } \\
\text { (IU/L) }\end{array}$ & $\begin{array}{l}\text { SGOT } \\
\text { (IU/L) }\end{array}$ & & \\
\hline A & $8.6 \pm 2.73$ & $56.9 \pm 0.54$ & $2.8 \pm 0.08$ & $10.6 \pm 0.30$ & $7.3 \pm 0.11$ & $2.3 \pm 0.42$ & $19.83 \pm 1.27$ \\
\hline B & $6.3 \pm 3.09^{a}$ & $46.8 \pm 0.48^{a}$ & $1.7 \pm 0.11^{\mathrm{a}}$ & $12.2 \pm 0.38^{a}$ & $7.0 \pm 0.14^{*}$ & $4.6 \pm 0.51^{a}$ & $15.17 \pm 2.34^{\mathrm{a}}$ \\
\hline $\mathrm{C}$ & $7.4 \pm 1.19^{b}$ & $52.8 \pm 0.39^{b}$ & $3.0 \pm 0.09^{b}$ & $11.0 \pm 0.43^{*}$ & $6.9 \pm 0.20^{*}$ & $3.5 \pm 0.37^{b}$ & $17.02 \pm 1.67^{b}$ \\
\hline $\mathrm{D}$ & $8.5 \pm 3.93^{b}$ & $59.7 \pm 1.21^{b}$ & $3.1 \pm 0.23^{b}$ & $10.0 \pm 0.25^{b}$ & $6.1 \pm 0.17^{b}$ & $3.1 \pm 0.61^{b}$ & $18.17 \pm 2.54^{b}$ \\
\hline
\end{tabular}

[Values: Mean \pm SEM of 6 rats in each dietary group].

A- Isoenergic normal fat group.

B-High fat- high cholesterol group (HFHC).

C- High fat- high cholesterol group +Lycopene (HFHC-LY).

D- High fat- high cholesterol group + Lycopene+RBO (HFHC-LY-RBO).

${ }_{p} \mathrm{p} \leq 0.05$ Significant between Group- A and Group-B.

${ }^{b} p \leq 0.05$ Significant between Group- B and Group-C and Group- D.

*: Non Significant $(p \geq 0.05)$.

in $(p \leq 0.05)$ enzymatic activity in the treated animals in comparison to the animals fed HFHC diets.

\subsection{Liver Function Biomarkers}

Group-B showed a significant increase $(p \leq 0.05)$ in the mean SGPT activity $(12.2 \pm 0.38 \mathrm{IU} / \mathrm{L})$ as compared to group-A $(10.6 \pm 0.30 \mathrm{IU} / \mathrm{L})$. Inclusion of lycopene singly $(11.0 \pm 0.43 \mathrm{IU} / \mathrm{L}), \quad(p \geq 0.05)$ and in blends $(10.0 \pm 0.25 \mathrm{IU} / \mathrm{L})$ to $\mathrm{HFHC}$ diets tended to reverse $(p \leq 0.05)$ the cataclysm in animals as shown in Table 4. Furthermore, mean SGOT levels in animals reared on $\mathrm{HFHC}$ diet $(7.0 \pm 0.14 \mathrm{IU} / \mathrm{L})$ and incorporation of lycopene singly $(6.9 \pm 0.20 \mathrm{IU} / \mathrm{L})$ did not show a sizeable change $(p \geq 0.05)$ as compared to their control counter parts $(7.3 \pm 0.11 \mathrm{IU} / \mathrm{L})$. However, coadministration of lycopene and RBO $(6.1 \pm 0.17 \mathrm{IU} / \mathrm{L})$ resulted in significant improvement $(p \leq 0.05)$ as compared to the ones fed HFHC diets $(7.0 \pm 014 \mathrm{IU} / \mathrm{L})$.

Serum alkaline phosphatase (ALP) activity in lycopene enriched diets showed a remarkable improvement $(p \leq 0.05)$ as compared to the corresponding HFHC diet fed experimental rats. In addition total protein content of HFHC rats showed a significant decrease $(p \leq 0.05)$. Lycopene fed singly and in blends with RBO caused a significant increase $(p \leq 0.05)$ as depicted in Table 4. 


\section{DISCUSSION}

Observations in changes in body weight, relative liver size and food consumption suggest that treatment with lycopene alone and along with RBO tended to nullify the affect of high fat high cholesterol diet. Furthermore, supplementation of experimental diets during the entire period of treatment did not result in any behavioural change, adverse affect or mortality in the animals.

The HFHC diet simulating cafeteria diet resulted in diet induced lipemic effect in experimental animals resulting in increased production of free radicals thereby disturbing the equilibrium. The lopsidedness of oxidants contributes to oxidative stress build up which further leads to increased accrual, biosynthesis and decreased efflux of lipid-lipoproteins. Lycopene treated animals resulted in increased excretion of cholesterol through bile acids and faecal lipids thereby regulating lipid-lipoprotein parameters which are in line with the previous reports [42-44]. In addition, the unsaponifiables present in RBO [45-48] exerted an additive effect with lycopene resulting in more distinct outcome. This may be brought about by profound influence of fat medium on increased bioavailability of lycopene [49-51]. Furthermore, lycopene mediated cholesterol excretion via enterohepatic circulation alleviated the upsurge and altered levels implicating its inhibitory effect on free radical generated hyperlipidemia thus helps in maintaining homeostasis.

Serum lipid indices are the markers for the development of cardiovascular diseases. Several studies have proven that elevated LDL-C levels with concomitant decreased HDL-C levels increases the risk for cardiovascular diseases [52-53]. Oxidative modification of LDL is a prerequisite for macrophage formation and plays a central role in promoting a complex chain of events leading to atherogenesis [5455]. On the other hand, increased HDL-C reduces the amount of deposited cholesterol in the endothelium and thus alleviating the risk of atherosclerosis. HDL retrieves excess cholesterol from macrophage foam cells undergoes efflux which is then transported to the liver for excretion through bile. TC/PL in HFHC diet fed rats increased significantly whereby the effect was negated in lycopene enriched groups suggestive of their hypocholesterolemic action. Sterol content of the membrane is an important determinant of its lipid state affecting molecular ordering of residual phospholipids resulting in reduced membrane fluidity thus favouring the liquid ordered phase to increase the thickness of lipid leaflet [56-57].
The enzymes viz. lipoprotein lipase (LPL), hepatic triglyceride lipase (HTGL), hydroxyl methyl glutaryl coenzyme A (HMG CoA); 1ecithin cholesterol acyl transferase (LCAT) and cholesterol ester synthetase (CES) are the key determinants in lipoprotein metabolism. LPL and HTGL are associated with hydrolysis of triglycerides present in circulating lipoproteins generating free fatty acids which are then taken up by hepatic and peripheral tissues. The resulting chylomicrons remnants begin the cascade for conversion of VLDL to LDL [58] which is taken by the liver via LDL receptors. The decline in the activity of LPL and HTGL points out reduced uptake of lipoproteins resulting in hypertriglyceridemia in HFHC rats. Conversely the rats treated with lycopene singly and in blend with RBO showed inhibition in alterations in lipid metabolizing enzymes corroborating the hypolipidemic effect of lycopene and RBO. The aberration in lipolytic enzymes of HFHC diet fed animals was in same vein with the earlier findings [59$60]$. On the other hand plasma LCAT is involved in "reverse cholesterol transport" where free cholesterol from peripheral tissues is transported as chlolesteryl esters to the liver for excretion through bile, thereby reducing the risk of CVD [61-63]. The decline in HDL-C in high fat fed rats can be attributed to decreased enzymatic activity confirming to the previous studies [64-65]. Conversely the antioxidative potential of lycopene and bioactive components of RBO contributed to increased HDL-C levels in experimental animals. Henceforth the increased LCAT enzymatic activity in both the lycopene enriched groups further justifies the increment substantiating the importance of the enzyme in HDL-C metabolism [66-67]. Cholesterol ester synthase (CES) in implicated in esterification and amalgamation of free cholesterol in chylomicrons and VLDL [68-69]. Recorded decrement of CES in lycopene enriched HFHC diet indicates decreased esterification and incorporation of free cholesterol to VLDL, thereby increasing its faecal excretion. The observed effects are consistent with other studies [70]. HMG CoA reductase on the other hand is the rate limiting enzyme in cholesterol biosynthesis [71]. The HMG$\mathrm{CoA} /$ mevalonate ratio is in inverse relation to the enzymic activity. Reduction in the enzyme activity of lycopene treated animals indicates decreased cholesterol biosynthesis and increased catabolism and efflux through bile acid secretion, consistent with previous reports [59-60].

High fat diet is associated with oxidative stress build up leading to several hyperlipidemic and hypercholesterolemic derived disorders. Elevated levels of TBARS is a clear indication of peroxidative 
degradation of the cell membranes leading to cellular and tissue damage and therefore weakening the antioxidant defense mechanism. This is evident from the decrease in antioxidative enzymes (GSHPx, CAT and SOD) further leading to increased free radical generation hence inflicting oxidative insult. To counteract the aforesaid mechanism, the non enzymatic antioxidant glutathione is utilized to quench the excess free radicals further depleting the levels. In the same vein, in response to altered oxidative stress biomarkers, natural free radical quencher uric acid is markedly increased to exhibit protection against the damage resulting from the imbalance between oxidants and antioxidants in favour of the former. Treatment with lycopene singly and in combination with RBO rendered protective effect and were able to resume the altered levels to near normal thereby ameliorating any further damage. The probable mechanism to facilitate the normalization of enzymatic levels and to mitigate free radical generation and accumulation is indebted to antioxidative capacity of lycopene and bioactive components of RBO. Results are consistent with previous studies demonstrating lycopene dissolved in olive oil reduced lipid peroxides levels and augmented glutathione levels as well as glutathione peroxidase (GSHPx) activity in male wistar rats fed for 31 days [72]. Another study demonstrated that lycopene supplementation at different doses for 2 weeks significantly improved the activity of antioxidant enzymes [73].

The altered levels of serum transaminases and alkaline phosphatase in HFHC diet fed rats clearly indicates dysfunctioning of the hepatic tissue resulting in impairment of liver membrane permeability thus allowing the escape of the enzymes into circulation [74]. The restoration of the enzymatic levels in treated animals was primarily a consequence of cumulative effect of antioxidative potential of lycopene and bioactive components of RBO thereby contributing to their hepatoprotective potential. Several studies have demonstrated the therapeutic index of lycopene and RBO in stabilizing liver dysfunctions and are in accordance with our results [59-60]. Bilirubin portends as biomarker for disturbed hepatocellular function. Increased haemolysis; obstructive jaundice or hepatotoxicity results in increased levels. The hydrophilic unconjugated form to be excreted through faeces is an outcome of coupling reaction of lipophilic conjugated bilirubin with UDP-GT (uridine diphosphateglucuronosyl transferase) [75-76]. Increased levels of total, conjugated and unconjugated bilirubin in HFHC rats are suggestive of malfunctioning of liver probably due to fatty infiltration and necrosis [77-78]. The profound influence of lycopene singly and in blend with RBO tended to nullify the effect and refurbish the levels. The protective effect can be attributed to their antilipemic and antioxidative potential confirming to previous studies [79-83]. Furthermore, upsurge protein levels in lycopene treated rats suggest the regeneration of liver cells henceforth corroborating their hepatoprotective property against deleterious effects of hyperlipidemia mediated oxidative stress as in accord with previous studies $[79,84]$.

\section{CONCLUSION}

The results clearly corroborate that admixture of lycopene and RBO is proficient in regulating the altered lipid-lipoprotein levels and lipid metabolizing enzymes in experimental animals. The effect is attributed to the cumulative antioxidative potential of the two to quench free radicals thereby maintaining cellular integrity against diet induced hyperlipidemia and oxidative stress. However, more comprehensive clinical studies are needed to evaluate the efficacy in various chronic diseases.

\section{ACKNOWLEDGEMENT}

The author likes to acknowledge University Grant Commission, New Delhi, India for providing financial assistance.

\section{CONFLICT OF INTEREST}

The author does not report any conflict of interest in relation to this study.

\section{REFERENCES}

[1] Sathivel A, Raghavendran HR, Srinivasan P, Devaki T. Antiperoxidative and anti-hyperlipidemic nature of Ulva lactucacrude polysaccharide on D-galactosamine induced hepatitis in rats. Food Chem Toxicol 2008; 46(10): 32623267.

https://doi.org/10.1016/j.fct.2008.07.016

[2] Epstein FM. Age and the cardiovascular system. New Eng J of Med 1992; 327: 173. https://doi.org/10.1056/NEJM199212103272408

[3] WHO. Diet, nutrition and the prevention of chronic diseases. Report of a WHO study group. Geneva, WHO; 2003

[4] Slim RM, Toborek M, Watkins BA, Boissonneault GA, Hennig B. Susceptibility to hepatic oxidative stress in rabbits fed different animal and plant fats. J Am Coll Nutr 1996; 15 (3): 289-294.

https://doi.org/10.1080/07315724.1996.10718600

[5] Andrej D, Biljana G, Rok D, Petra K, Julijana K Pharmaceutical nanotechnology nanosized particles of orlistat with enhanced in vitro dissolution rate and lipase inhibition. Int J Pharm 2010; 396: 149-155. https://doi.org/10.1016/j.ijpharm.2010.06.003 
[6] Anila L, Vijayalakshmi NR. Flavonoids from Emblica officinalis and Mangifera indica-effectiveness for dyslipidemia. J of Ethno 2002; 79: 81-87. https://doi.org/10.1016/S0378-8741(01)00361-0

[7] Minhajuddin $\mathrm{M}$, Beg $\mathrm{ZH}$, lqbal J. Hypolipidemic and antioxidant properties of tocotrienol rich fraction isolated from rice bran oil in experimentally induced hyperlipidemic rats. Food Chem Toxicol 2005; 43 (5): 747-753. https://doi.org/10.1016/j.fct.2005.01.015

[8] Gorinstein S, Leontowicz H, Leontowicz M, Drzewiecki J, Najman K, Katrich E. Raw and boiled garlic enhances plasma antioxidant activity and improves plasma lipid metabolism in cholesterol-fed rats. Life Sci 2006; 78 (6): 655663. https://doi.org/10.1016/j.lfs.2005.05.069

[9] Harnafi H, Caid HS, Bouanani NH, Aziz M, Amrani S. Hypolipemic activity of polyphenol-rich extracts from Ocimum basilicum in triton WR-1339-induced hyperlipidemic mice. Food Chem 2008; 108: 205-212. https://doi.org/10.1016/j.foodchem.2007.10.062

[10] Rao AV, Agarwal S. Role of lycopene as antioxidant carotenoid in the prevention of chronic disease: A review. Nutr Res 1999; 19: 305-323.

https://doi.org/10.1016/S0271-5317(98)00193-6

[11] Di Mascio $P$, Kaiser $S$, Sies $H$. Lycopene as the most efficient biological carotenoid. Arch Biochem Biophys 1989; 274: 532.

https://doi.org/10.1016/0003-9861(89)90467-0

[12] Cavusoglu K, Oruc E, Yapar K, Yalcin E. Protective effect of lycopene against mercury-induced cytotoxicity in albino mice: Pathological evaluation. J Environ Biol 2009; 30 (5): 807-814.

[13] Kim AY, Jeong YJ, Park YB, Lee MK, Jeon SM, McGregor RA, Choi MS. Dose dependent effects of lycopene enriched tomato-wine on liver and adipose tissue in high-fat diet fed rats. Food Chem 2012; 130 (1): 42-48.

https://doi.org/10.1016/j.foodchem.2011.06.050

[14] Shi J, Maguer ML, Kakuda Y, Liptay A, Niekamp F. Lycopene degradation and isomerization in tomato dehydration. Food Res Int 1999; 32(1): 15-21. https://doi.org/10.1016/S0963-9969(99)00059-9

[15] Ghafoorunssia, Dietary lipids and heart disease- the Indian context. Natl Med J India 1994; 7(6): 270-276.

[16] Seetharamaiah GS, Chandrasekhara N. Studies on hypocholesterolemic activity of rice bran oil. Athero 1989; 78 : 219-223.

https://doi.org/10.1016/0021-9150(89)90226-8

[17] Rong N, Ausman LM, Nicolosi RJ. Rice bran oil decreases plasma LDL cholesterol by inhibiting dietary cholesterol absorption. FASEB J 1994; 8A162.

[18] Rong N, Ausman LM, Nicolosi RJ. Oryzanol decreases cholesterol absorption and aortic fatty streaks in hamsters. Lipids 1997; 32: 303-309. https://doi.org/10.1007/s11745-997-0037-9

[19] Raghuram TC, Rukmini C. Nutritional significance of rice bran oil. Ind J Med Res 1995; 102: 241-244.

[20] Reeves PG, Nielsen FH, Fahey Jr GC. AIN-93 Purified diets for laboratory rodents: Final report of the American institute of nutrition adhoc writing committee on the reformulation of the AIN-76 a rodent diet. J Nutr 1993; 123: 1939-1951.

[21] OECD, Guidelines of testing of chemicals, 423 acute oral toxicity (acute toxic class method).2001.

[22] Friedewald WT, Levy RI, Fredrickson DS. Estimation of the concentration of LDL-C in plasma, without use of the preparative ultracentrifuge. Clin Chem 1972; 18: 499-502.

[23] Caraway WT. Standard methods of clinical chemistry, D. Seligson (Eds) New York and London: Academic press; 1963, 4 pp. 239.
[24] Reitman, Frankel. Am. J. Clin. Pathol. 1957; 28: 56-63, In: Haoks Physiological Chemistry. Oser BL (ed), New Delhi: Tata McGraw Hill Publishers; 1979, pp.1125-1127.

[25] Belfield A, Goldberg DM. Colorimetric determination of alkaline phosphatase activity. Enzym 1971; 12: 561-568.

[26] Folch J, Lees M, Stanley GHS. A simple method for the isolation and purification of total lipids from animal tissue. $J$ Biol Chem 1957; 226: 497-507.

[27] Mosback EH, Klenisky HJ, Hal P, Kendall EE. Determination of deoxycholic acid and cholic acid in bile. Arch Biochem Biophys 1954; 51: 402-409. https://doi.org/10.1016/0003-9861(54)90495-6

[28] Gutteridge JMC. Bleomycin detectable iron in knee joint synovial fluid from arthritic patients and its relationship to extracellular antioxidant activities of ceruloplasmin, transferrin and lactoferrin. Biochem J 1987; 245: 415-421. https://doi.org/10.1042/bj2450415

[29] Satoh K. Serum lipid peroxide in cerebrovascular disorders determined by a new colorimetric method. Clinica Chimica Acta 1978; 90: 37-43.

https://doi.org/10.1016/0009-8981(78)90081-5

[30] Ellman GL. Tissue sulphydryl groups. Arch Biochem Biophys 1959; 82: 70-77.

https://doi.org/10.1016/0003-9861(59)90090-6

[31] Ohkawa H, Oshishi N, Yagi K. Assay of lipid peroxides in animal tissues by thiobarbituric acid reaction. Ann Biochem 1979; 95: 351.

https://doi.org/10.1016/0003-2697(79)90738-3

[32] Sedlak J, Lindsey RH. Estimation of total protein bound and non protein sulphydral groups in tissues with ellman's reagent. Ann Biochem 1968; 25: 192. https://doi.org/10.1016/0003-2697(68)90092-4

[33] Necheles TF, Bolas TA, Allen DM. Erythrocyte glutathione peroxidase deficiency and haemolytic disease of the new born infant. J Paed 1968; 72 (3): 31.

https://doi.org/10.1016/S0022-3476(68)80202-1

[34] Luck H. Catalase, in: Methods of enzymatic analysis. Berameyer Hansulrich (Eds), New York, London: Academic Press; 1971; pp. 855.

[35] Kono Y. Generation of superoxide radical during autooxidation of hydroxylamine and an assay for SOD. Arch Biochem Biophy 1978; 186: 189. https://doi.org/10.1016/0003-9861(78)90479-4

[36] Lowry $\mathrm{OH}$, Rosebrough NJ, Farr AL, Randall RJ. Protein measurement with the folin phenol reagent. J Biol Chem 1951; 193: 265-275.

[37] Korn ED. Lipoprotein lipase (clearing factor). Methods Enzymol 1962; 5: 542-545. https://doi.org/10.1016/S0076-6879(62)05273-8

[38] Hitz J, Steinmetz J, Siest G. Plasma lecithin: cholesterol acyl transferase-reference values and effects of xenobiotics. Clin Chim Acta 1983; 133: 85-96. https://doi.org/10.1016/0009-8981(83)90023-2

[39] Kothari HV, Miller BF, Kritchevsky D. Aortic cholesterol esterase: characteristics of normal rat and rabbit enzyme. Biochem Biophys Acta 1973; 296: 446-454. https://doi.org/10.1016/0005-2760(73)90102-1

[40] Schmidt FH, Stork H, Dahl K. Methods in enzymatic analysis, in: H.V. Bergmeyer, (Eds.), New York: Academic Press; 1974, pp. 819.

[41] Rao AV, Ramakrishnan S. Indirect assessment of hydroxymethylglutaryl- Co A reductase (NADPH) activity in liver tissue. Clin Chem 1975; 21: 1523-1525.

[42] Verghese M, Richardson JE, Boateng J, Shackelford LA, Howard C, Walker LT, Chawan CB. Dietary lycopene has a protective effect on cardiovascular disease in New Zealand male rabbits. J Biol Sci 2008; 8: 268-277. https://doi.org/10.3923/jbs.2008.268.277 
[43] Hu MY, Li YL, Jiang CH, Liu ZQ, Qu SL, Huang YM. Comparison of lycopene and fluvastatin effects on atherosclerosis induced by a high fat diet in rabbits. Nutr 2008; 24: 1030-1038.

https://doi.org/10.1016/j.nut.2008.05.006

[44] Lee LC, Wei L, Huang WC, Hsu YJ, Chen YM, Huang CC. Hypolipidemic effect of tomato juice in hamsters in high cholesterol diet-induced hyperlipidemia. Nutr 2015; 7: 1052510537. https://doi.org/10.3390/nu7125552

[45] Sharma RD, Rukmini C. Rice bran oil and hypocholesterolemia in rats. Lipids 1986; 21: 715-717. https://doi.org/10.1007/BF02537246

[46] Sharma RD, Rukmini C. Hypocholesterolemic activity of unsaponifiable mater of rice bran oil. Ind J Med Res 1987; 85: 278-281

[47] Seetharamaiah GS, Chandrasekhara N. Studies on hypocholesterolemic activity of rice bran oil. Athero 1989; 78 : 219-223.

https://doi.org/10.1016/0021-9150(89)90226-8

[48] Seetharamaiah GS, Chandrasekhara N. Effect of oryzanol on cholesterol absorption and biliary and fecal bile acid in rats. Ind J Med Res 1990; 92: 471-475.

[49] Arranz S, Martínez-Huélamo $M$, Vallverdu-Queralt A, Valderas-Martinez $P$, Illán $M$, Sacanella $E$, Escribano $E$, Estruch R, Lamuela-Raventos RM. Influence of olive oil on carotenoid absorption from tomato juice and effects on postprandial lipemia. Food Chem 2015; 168: 203-210. https://doi.org/10.1016/j.foodchem.2014.07.053

[50] Colle IJ, Lemmens L, Van Buggenhout S, Met K, Van Loey AM, Hendrickx ME. Processing tomato pulp in the presence of lipids: The impact on lycopene bioaccessibility. Food Res Int 2013; 51: 32-38.

https://doi.org/10.1016/j.foodres.2012.11.024

[51] Cooperstone JL, Ralston RA, Riedl KM, Haufe TC, Schweiggert RM, King SA, Schwartz SJ. Enhanced bioavailability of lycopene when consumed as cis-isomers from tangerine compared to red tomato juice, a randomized, cross-over clinical trial. Mol Nutr Food Res 2015; 59: 658669.

https://doi.org/10.1002/mnfr.201400658

[52] Parthasarathy S. High density lipoprotein inhibits the oxidative modification of low density lipoprotein. Biochim Biophys Acta 1990; 1044: 275-283. https://doi.org/10.1016/0005-2760(90)90314-N

[53] Reiner Z, Tedeschi-Reiner E. Atherosclerosis-a paradox of Eastern European countries. Athero 2006; 7(3): 461. https://doi.org/10.1016/S1567-5688(06)81854-4

[54] Witztum JL. The oxidation hypothesis of atherosclerosis. Lancet 1994; 344: 793-795.

https://doi.org/10.1016/S0140-6736(94)92346-9

[55] Terasaka N, Wang N, Charvet LY, Tall AR. High-density lipoprotein protects macrophages from oxidized low-density lipoprotein-induced apoptosis by promoting efflux of 7ketocholesterol via ABCG1. Proc Natl Acad Sci USA 2007; 104 (38): 15093-15098. https://doi.org/10.1073/pnas.0704602104

[56] Marsch D, Knowles PF, Rattle H W E. Magnetic Resonance of Biomolecules, New York: John Wiley and Sons; 1976, pp.237.

[57] Narasimhamurthy K, Raina PL, Hariharan K. Effect of long term feeding of high fat diets on growth, plasma and tissue lipids in rats. J Food Sci Technol 1997; 34 (4): 303-310.

[58] Goldberg IJ. Lipoprotein lipase and lipolysis: central roles in lipoprotein metabolism and atherogenesis. J Lipid Res 1996; 37: 693-707.

[59] Sheriff SA, Devaki T. Lycopene stabilizes lipoprotein levels during D-galactosamine/ lipopolysaccharide induced hepatitis in experimental rats. Asian Pac J Trop Biomed 2012; 2(12): 975-980.

https://doi.org/10.1016/S2221-1691(13)60009-X

[60] Chauhan K, Chauhan B. Rice bran oil and oryzanol attenuates dyslipidemia and oxidative stress in atherogenic diet fed rats. Int J of Med and Pharm Sci 2015; 5 (4): 53-68.

[61] Martinez LO, Jacquet S, Terce F, Collet X, Perret B, Barbaras R. New insight on the molecular mechanisms of high density lipoprotein cellular interaction. Cell Mol Life Sci 2004; 61: 2343-2360. https://doi.org/10.1007/s00018-004-4087-y

[62] Zou YP, Lu YH, Wei DZ. Hypocholesterolemic effects of a flavonoid-rich extract of Hypericum perforatum L. in rats fed a cholesterol-rich diet. J Agric Food Chem 2005; 53: 24622466. https://doi.org/10.1021/jf048469r

[63] Wang Y, Li Y, Sun A, Wang F, Yu G. Hypolipidemic and antioxidative effects of aqueous enzymatic extract from rice bran in rats fed a high-fat and cholesterol diet. Nutr 2014; 6 : 3696-3710. https://doi.org/10.3390/nu6093696

[64] Jonas A. Lecithin-cholesterol acyltransferase in the metabolism of high-density lipoproteins. Biochim Biophys Acta 1991; 1084: 205-220. https://doi.org/10.1016/0005-2760(91)90062-M

[65] Kunnen S, Eck MV. Lecithin:cholesterol acyltransferase: old friend or foe in atherosclerosis? J Lipid Res 2012; 53(9): 1783-1799.

https://doi.org/10.1194/jlr.R024513

[66] Asztalos BF, Schaefer EJ, Horvath KV, Yamashita S, Miller $M$, Franceschini $G$, Calabresi L. Role of LCAT in HDL remodeling: investigation of LCAT deficiency states. J Lipid Res 2007; 48: 592-599. https://doi.org/10.1194/jlr.M600403-JLR200

[67] Jain KS, Kathiravan M K, Somani RS, Shishoo CJ. The biology and chemistry of hyperlipidemia. Bioorg and Med Chem 2007; 15: 4674-4699. https://doi.org/10.1016/j.bmc.2007.04.031

[68] Klein RL, Rudel LL. Cholesterol absorption and transport in thoracic duct lymph lipoproteins of nonhuman primates. Effect of dietary cholesterol level. J of Lipid Res 1983; 24 343-356.

[69] Rudel LL, Shelness GS. Cholesterol esters and atherosclerosis-a game of ACAT and mouse. Nat Med 2000; 6: 1313-1314 https://doi.org/10.1038/82110

[70] Upaganlawar AB, Balaraman R. Cardioprotective effect of vitamin $E$ in combination with lycopene on lipid profile, lipid metabolizing enzymes and infarction size in myocardial infarction induced by isoproterenol. Pharmacol 2012; 3(7): 215-220.

[71] Goldstein J L, Brown MS. Regulation of the mevalonate pathway. Nature 1990; 343: 425-430. https://doi.org/10.1038/343425a0

[72] Bansal P, Gupta SK, Ojha SK, Nandave M, Mittal R, Kumari $S$, Arya DS. Cardioprotective effect of lycopene in the experimental model of myocardial ischemia-reperfusion injury. Mol Cell Biochem 2006; 289: 1-9. https://doi.org/10.1007/s11010-006-9141-7

[73] Breinholt V, Lauridsen ST, Daneshvar B, Jakobsen J. Doseresponse effects of lycopene on selected drug-metabolizing and antioxidant enzymes in the rat. Cancer Lett 2000; 154: 201-210. https://doi.org/10.1016/S0304-3835(00)00401-8

[74] Sudhahar V, Kumar S A, Varalakshmi P. Effect of lupeol and lupeol linoleate on lipemic - hepatocellular aberrations in rats fed a high cholesterol diet. Mol Nutr Food Res 2006; 50(12): 1212-1219. https://doi.org/10.1002/mnfr.200600134 
[75] Soliman AM. Potential impact of Paracentrotus lividus extract on diabetic rat models induced by high fat diet/streptozotocin. J Basic and App Zoology 2016; 77: 8-20. https://doi.org/10.1016/j.jobaz.2016.01.001

[76] Hull TD, Agarwal A. Bilirubin: a potential biomarker and therapeutic target for diabetic nephropathy. Diab 2014; 63: 2613- 2616.

https://doi.org/10.2337/db14-0691

[77] Nanji AA, Tsukamoto H, French SW. Relationship between fatty liver and subsequent development of necrosis, inflammation and fibrosis in experimental alcoholic liver disease. Exp Mol Pathol 1989; 51(2):141-148. https://doi.org/10.1016/0014-4800(89)90014-2

[78] Gilat T, Leikin-Frenkel A, Goldiner I, .Juhel C, Lafont H, Gobbi D, Konikoff FM. Prevention of diet-induced fatty liver in experimental animals by the oral administration of a fatty acid bile acid conjugate (FABAC). Hepatology 2003; 38: 436-442. https://doi.org/10.1053/jhep.2003.50348

[79] Ahuja KD, Pittaway JK, Ball MJ. Effects of olive oil and tomato lycopene combination on serum lycopene, lipid profile, and lipid oxidation. Nutr 2006; 22: 259-265. https://doi.org/10.1016/j.nut.2005.07.015
[80] Wilson TA, Nicolosi RJ, Woolfrey B, Kritchevsky D. Rice bran oil and oryzanol reduce plasma lipid and lipoprotein cholesterol concentrations and aortic cholesterol ester accumulation to a greater extent than ferulic acid in hypercholesterolemic hamsters. J Nutr Biochem 2007; 18: 105-112.

https://doi.org/10.1016/j.jnutbio.2006.03.006

[81] Erdman Jr JW, Ford NA, Lindshield BL. Are the health attributes of lycopene related to its antioxidant function? Arch Biochem Biophys 2009; 483: 229-235. https://doi.org/10.1016/j.abb.2008.10.022

[82] Shakib MC, Gabrial S, Gabrial G. Rice bran oil compared to atorvastatin for treatment of dyslipidemia in patients with type 2 diabetes. J of Med Sci 2014; 15(2): 95-102. https://doi.org/10.3889/oamjms.2014.017

[83] Aidoud A, Ammouche A, Garrido M, Rodriguez AB. Effect of lycopene-enriched olive and argan oils upon lipid serum parameters in wistar rats. J Sci Food Agric 2014; 94(14): 2943-2950. https://doi.org/10.1002/jsfa.6638

[84] Maheswari MU, Rao PGM. Antihepatotoxic effect of grape seed oil in rat. Ind J Pharm 2005; 37(3): 179-182. https://doi.org/10.4103/0253-7613.16216 